\title{
7. Reporting the Asian tsunami: Ethical issues
}

\section{ABSTRACT}

This article explores the ethical issues faced by New Zealand journalists reporting a disaster. Journalists who travelled to Asia to report on the 2004 tsunami were asked to complete an online survey containing a mixture of Likert scale and open-ended questions. Of the 20 journalists known to have travelled to Asia to cover the tsunami, 13, or 65 percent, took part in the survey. Many were confronted with ethical dilemmas. These problems were compared to the literature on reporting disasters, and triangulated through a one-on-one interview with a psychologist working with survivors of the tsunami. This comparison raised further issues not mentioned by the respondents. A second survey was sent out to elicit responses to these further issues. Four out of 20 replied, and their responses were compared to the literature and to the relevant codes of ethics. The results suggest New Zealand journalists have a strongly ethical approach but that there is a lack of awareness of some significant ethical issues. This indicates the level of support and training given to those covering such events needs revision. Further research on the issues raised would be fruitful.

\section{JAMES HOLLINGS \\ Massey University}

\section{Background}

DHE TSUNAMI of Boxing Day 2004 was among the worst natural dis asters of the past century. The loss of life is estimated at over 300,000,

with many still missing. Many experienced journalists described it as the worst disaster, by far, they had covered. For example, CNN anchor Aaron Brown, who covered the September 11 attacks, the Columbine High School shootings, and the aftermath of the Columbia space shuttle disaster, states: 
Indonesia after the tsunami was the worst of it - times a hundred...we were literally tripping over bodies ... People who have been around death like that, it has a peculiar and memorable smell to it, and it's not something that you easily rid yourself of (Dart, 2005).

The scale of the disaster was reflected in the level of media coverage; an analysis by Reuters estimated 35,000 reports in the two months after the event in English language newspapers alone. This compared with 33,620 reports for the top 10 emergencies combined during the previous year. (MacLean, 2005). New Zealand was among those countries which showed a strong interest; at least 20 journalists from prominent media organisations were sent to cover the immediate aftermath and the loss of New Zealand lives; these included both the state-owned and privately owned television channels (TV1 and TV3), the state-owned radio broadcaster (Radio New Zealand) and both big newspaper chains (APN and Fairfax).

Reporting a disaster raises a number of unusual ethical dilemmas for the working journalist. Commentators suggest these include whether to become a participant, to provide help for those afflicted, or to remain in the journalist's traditional role of an observer. Another ethical concern is how to report death, in particular the kinds of pictures of dead bodies that should be shown, if at all. To what degree should reporters reflect the uncomfortable sights and smells of the aftermath of a disaster when they know families and friends of the victims are watching, reading or listening? Other issues include, to what degree should reporters intrude upon the grief of the survivors? This is true of any situation involving a fatality but has particular importance in an event like this when the fate of many of loved ones was uncertain. Less discussed, but an issue supported by research conducted for this article, is the effect on the disaster survivors themselves, particularly children, of being interviewed; the effects on the journalists themselves of witnessing so much trauma, and the role of their employers in managing this. The use of traditional media techniques such as staging photos is another well-known issue; again it assumes a particular flavour in such an emotionally fraught situation. Likewise, the role of photo opportunities, particularly by aid organisations in developing countries, raises issues when the subjects may be less than aware of their purpose or their own rights. Another problem is the conflict between the priorities of aid, medical or government agencies and those of the media. 


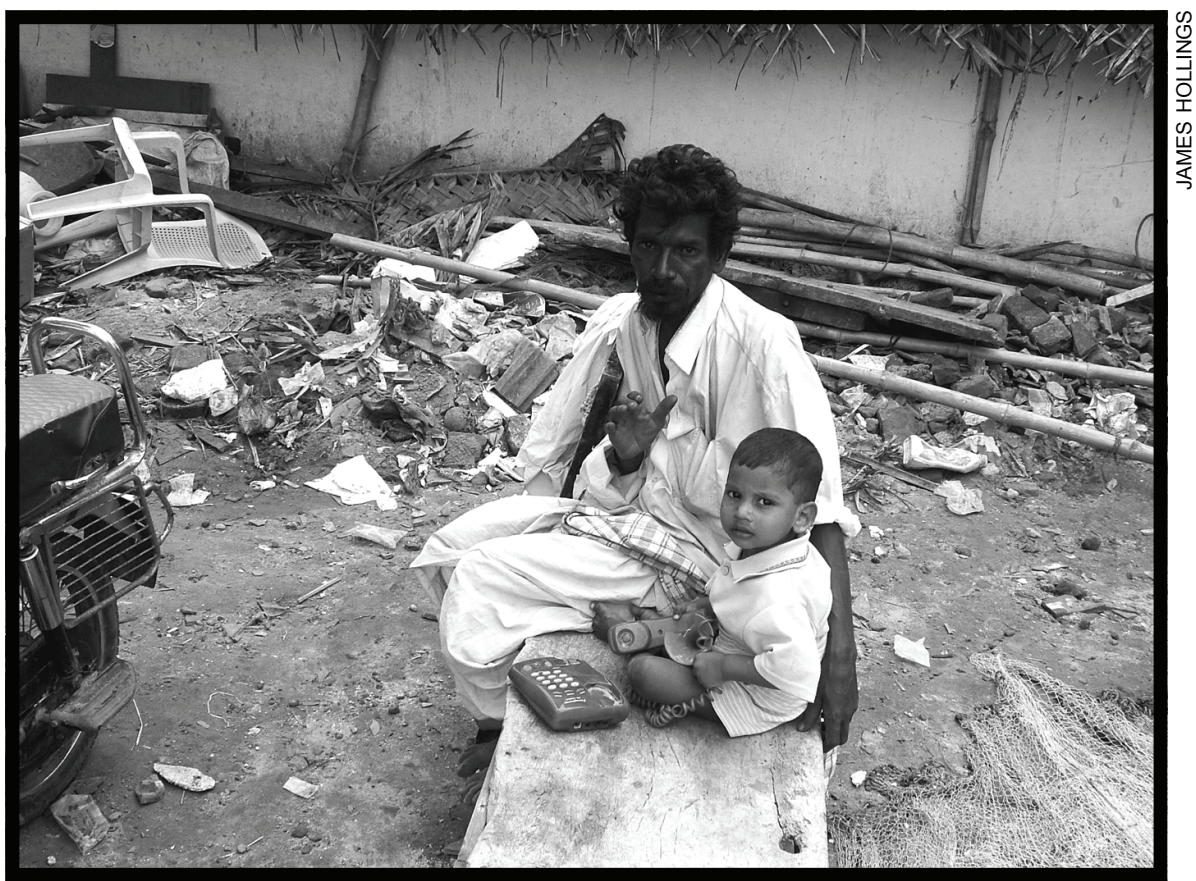

Ethical issues: Should reporters intrude upon the grief of survivors?

This study suggests the nature of this particular disaster threw up many of these dilemmas. This article aims to explore the ethical issues inherent in reporting on such events and compare these to the codes of ethics operating in New Zealand to assess the codes' relevance. It then looks at how New Zealand journalists responded to these ethical issues, to assess what changes might be useful both in ethics codes and journalistic practice.

\section{The literature}

Many of the issues raised above have been well-canvassed in the literature and in the wider journalism community, while others are only beginning to emerge as ethical points worthy of study. Here they are examined one by one. Initially this will be done by exploring the codes of ethics used by New Zealand journalism organisations, and then by examining the relevant literature.

There are three main codes used by New Zealand media. Broadcasters are covered by the Broadcasting Standards Authority. It has codes of practice 
for free-to-air TV, pay TV and radio, plus a body of case law built up about its decisions. The print media is self-regulated by the Press Council, which has its own code of practice. Of the two corporations which own most of New Zealand's newspapers, Fairfax New Zealand has its own code of practice, while APN does not. The main trade union covering journalists, the Amalgamated Engineering, Printing and Allied Trades Union, also has a code of practice for journalists.

Turning to the issues in more detail, Richards (2005, p. 134) argues that reporting on grief can be broadly divided into two categories:

1. those associated with interviewing and reporting

2. those associated with representation of the reports and interviews when printed or broadcast.

As the ethics around the second category are much better defined, I would like to deal with those first, then move on to the first category, which is more problematic.

There is extensive debate about the extent to which graphic images of death should be represented. While some argue against any form of self-censorship, most Western news media tend to avoid showing pictures of dead bodies unless to do so would mislead by omission or underplay what has happened. A good summation of this can be found in Cote and Simpson's Covering Violence (2000, p. 138). The codes of ethics adhered to by New Zealand's main media organisations also follow this line. All require editors to take into consideration norms of decency and good taste, while not distorting the news by omission. Generally this has been interpreted to mean images of dead bodies are not shown, except in special circumstances. During the tsunami, for example, TVNZ tended to show wide shots, or shots of hands or feet, rather than corpses as a whole, though it did show some (C. Glennie, personal communication, 17 June 2005).

Other questions of representation are relatively clear cut. There are clear boundaries laid down in the industry's ethical codes which prevent digital manipulation of images without informing the audience. Staging photos - for example posing people or groups is not explicitly covered, although all codes have general provisions requiring media to behave honestly without deliberately misinforming their audience. This reflects what is known about industry practice: that the use of staged photos is widespread. A survey of Australian press photographers found that most tended to follow a 'shoot first and 
ask questions later' rule (Griffin, 1995, p. 25). That is, they tend to take the shot and leave it to their editors to debate the ethics of it. The survey found, however, that the photographers had clear values on which they based their approach, i.e. there were definitely limits to what they would do to get shots, and to what degrees of posing they would countenance. The survey found they had fairly similar attitudes to US press photographers. Some commentators would like to see this approach tightened up. Wheeler argues that media organisations should sign up to a pledge not to use staged or manipulated photos (Wheeler, 2002, p. 196).

So much for the representation of grief. Turning now to the ethics around gathering stories about the grief-stricken, one of the first issues journalists must face at a disaster scene is whether to become a participant, to help those afflicted, or remain an observer. The New Zealand codes are silent on this issue, but there is much in the wider literature about the appropriate response, and the teleological or deontological underpinnings of these ethical choices (see for example, Hirst, 2005, p. 9). Much journalism training prescribes that journalists should not report when they can act immediately to save life (see for example, the Dart Center's guidelines on covering disasters, Dart, 2005). There are numerous well-documented examples of situations in which journalists have ignored this, such as the famous Kevin Clark photo of a vulture stalking a child famine victim. One reporter who faced a related issue during the tsunami was Kimina Lyall, the South-east Asian correspondent for The Australian. She was there as the waves arrived and witnessed friends being washed away. After helping organise rescue efforts, she began filing stories for her newspaper. Although the immediate need to provide assistance had passed, in the days following she felt torn between the pressure to fulfil her journalistic obligations and the need to stay with the community of friends she had been with when the tsunami hit, 'through the next terrible days of finding and identifying bodies and offering support to the injured and bereaved' (K. Lyall, personal communication, 20 September 2005).

When it comes to intruding upon the grief of those affected by a disaster, all the NZ codes are clear. Standard 6(e) of the free to air TV code says: 'Broadcasters should take particular care when dealing with distressing situations, and with grief and bereavement' (BSA, 2004). The Press Council is more specific: 'Those suffering from trauma or grief call for special consideration, and when approached, or enquiries are being undertaken, careful at- 
tention is to be given to their sensibilities' (NZPC, 1999). The Fairfax and union codes have similar provisions.

The relatively specific nature of the ethical guidelines above reflects the importance of this issue for journalists, and the frequency with which they have to confront it in their work. As Richards says, the reporting of deaths of individuals or the grief of those bereaved raises 'some of the most contentious ethical dilemmas facing journalists today' (p. 135). There is an increasing body of literature arguing that the kind of provisions in the codes of ethics listed above may not go far enough in protecting disaster or trauma victims. Richards argues that the medical model of informed consent is relevant: 'On occasion ... those caught up in crisis and trauma are reduced to a state that makes it difficult for them to respond coherently or make a valid judgment about the implications of speaking to a reporter or posing for a photographer' (p. 145). Extra weight is lent to this argument by evidence which suggests that people in developing countries may be more psychologically affected by disasters than those in developed countries (Norris, 2002, p. 245).

Other studies have shown that journalists can have either significant positive or negative effects on victims' recovery from mental trauma, depending on the approach taken. US researchers Nelson and Nelson (2001) have done a lot of work on how journalists should interview disaster victims. They argue journalists should ask permission to interview, discuss the boundaries of the interview and think carefully about things such as body language.

It is unlikely such a prescriptive approach would find much favour with deadline-pressed journalists competing for a major story. But an Australian research project offers some good reasons for making at least some effort. The Newsroom and Trauma Research Project found that journalists could improve victims' prospects for recovery - and make being part of a story a positive experience - by using strategies which passed some control to the interviewee, e.g by providing some of the questions in advance and making an extra effort to check facts (Sykes, 2003, p. 10). If confirmed, the findings offer hope that the common perception that journalists doing 'death knock' stories are vultures could be reversed.

One issue not specifically covered in the above research, but which has emerged as a particular concern in research for this article, is that of dealing with child disaster survivors. Laura Conrad, of Save the Children, felt journalists covering the tsunami overstepped the mark. 
At one point, with Ben Brown and with another BBC World Service radio reporter, I did have to step in as they were continually pressing children on what their experiences of the tsunami were... I'm all for showing the distress, that's really important, but there are limits. And for children there has to be really appropriate engagement. (Dart, 2005)

Psychologists suggest children who have experienced trauma need to be treated very sensitively. The Seattle-based Dart Center for journalism and trauma has guidelines on this point:

Children are more vulnerable to trauma because of their size, age and dependence. Prior trauma, past mental health problems or a family history of such problems may increase a child's risk ... Traumatized children may want to tell their story, but it may not be in their best interests to be interviewed, and in some circumstances it can exacerbate their exposure to trauma. (Dart, 2005)

The New Zealand codes of ethics touch on the subject, but without identifying the more subtle ways in which journalists could be unwittingly prolonging survivors' trauma. The free to air TV Broadcasting Code says: 'Children's vulnerability must be a prime concern to broadcasters. When consent is given by the child, or by a parent or someone in loco parentis, broadcasters shall satisfy themselves that the broadcast is in the best interest of the child' (BSA, 2004). The Press Council's code requires that editors should have 'particular care and consideration for reporting on and about children and young people' (NZPC, 1999).

Another emerging area is the effect of reporting disasters on the journalists themselves. There is a growing body of literature accumulating on the effects on journalists of being in a traumatic situation. Cote et al suggest unresolved trauma can affect the quality of journalists' work (2000, pp. 5051) Hence the management of the emotional toll of covering a disaster can be an ethical consideration not only for those responsible for journalists' welfare - their employers - but also for the journalists themselves, in that the kind of story they write may reflect their own state of emotional health. The extent to which journalists and other disaster workers are affected by post traumatic stress disorder (PTSD) is a subject which is still under researched. PTSD is usually defined as an anxiety disorder characterised by intrusive 
reminders, avoidance and hyperarousal. It is usually contracted either by direct exposure to a traumatic stressor, such as seeing dead bodies, or in the case of secondary traumatic stress, from indirect exposure, such as being exposed to the grief of primary victims. PTSD has been found in war journalists (Feinstein, Owen \& Blair, 2002, pp. 1571-72). Secondary traumatic stress (also called vicarious trauma and compassion fatigue) is less-researched, but is likely in journalists who report on disasters (Palm, Polusny and Follette, 2004 , p. 75). As a recent NZ study by a former journalist showed, this is exacerbated if the person engaging with trauma victims has unresolved experiences of trauma themselves (Hargrave, 2005).

There is nothing in the NZ codes of ethics about sending inexperienced reporters into such situations without proper support, or about providing counselling and/or debrief afterwards even for experienced reporters. Most employers would probably regard it as an issue to be dealt with through legislation or employment contracts. This is understandable; recent changes to New Zealand's Health and Safety in Employment Act recognise stress as a workplace hazard that is the responsibility of employers (OSH, 2003). In fact, in 2000 a former police photographer won nearly $\$ 250,000$ in damages for PTSD resulting from exposure to horrific crime scenes (CTU, 2002). Even though it has been dealt with by legislation in New Zealand, it is clear that some writers regard it as a wider ethical issue. The BBC is one news organisation that requires its journalists to undergo a HEFAT (Hostile Environment and First Aid Training) course before covering wars or major natural disasters. This provides training in, among other things, post-traumatic stress disorder (BBC, 2005).

Another issue which came up in research for this article was the conflict between the priorities of news organisations and those of humanitarian and security concerns. All the codes address this with general provisions requiring media organisations to maintain their editorial integrity and independence.

A final consideration raised in the literature is whether codes of ethics make much difference to journalists' behaviour. Tucker suggests that in-house codes can change ethical approaches in newsrooms. But he says merely introducing the codes may not be enough: 'I found some of New Zealand's most ethically-stressed media workplaces, television news, for example, already have such codes, but they appeared to make little direct impact on the 
culture at coal-face level' (Tucker, 2001, p. 213). Varley found similar attitudes in Australia in her study of the effect of introducing a code of practice at the Melbourne's Herald and Weekly Times Ltd in 1994 (Varley, 1997). Nevertheless, Lealand (2004) has found that there is still a hunger for ethical guidance among NZ journalists, who listed it top equal with media law in training needs.

\section{Methodology}

The data for this article were gathered by two research methods. Firstly, a survey was undertaken of 20 journalists known to have travelled to Asiaincluding Indonesia, India, Sri Lanka and Thailand - to report on the effects of the Boxing Day tsunami. Their names were gathered by contacting all the major media organisations and asking who had represented them. An invitation to take part in the survey was emailed to all 20 journalists. The email included an information sheet and a link to an on-line questionnaire. The questionnaire consisted of 25 questions on a range of ethical issues, plus general comments on their experience. Respondents replied by means of a mixture of a modified Likert scale and general comments. Anonymity was guaranteed by means of a non-specific identifier used by the website administrator. Some of the questions asked the journalists to comment on their employers, and it was thought anonymity would provide them with more freedom to do so. The survey was assessed as low-risk by Massey University's ethics committee. It was emailed to the journalists in late April 2005, approximately five months after the tsunami. After one week, 11 journalists had filled out the questionnaire. A follow-up email was sent to all journalists, after which two more replies were received. The results were downloaded onto a spreadsheet and analysed by experience, time in the disaster area, and overall response. It was compared to the literature, and triangulated through a one-on-one interview with a psychologist working with tsunami survivors. Further questions arose, which were put to all 20 journalists in a second, eight-question survey, using the same method as above. Four replies were received.

\section{Results and discussion}

The 13 journalists who replied to the first survey had a wide range of experience. Their average number of years experience was 12.5 and the median 
9.5. Six had 15 years or more; five less than eight, and one had less than two years' experience. Time spent in the disaster areas ranged from one to 28 days, with an average of 11 and a median of eight days. Only one spent less than three days there.

Broadly - and speaking five months afterwards - the journalists thought the overall media coverage of the tsunami was satisfactory: four said it was excellent, six good, while three rated it fair. They were also happy with the way their organisation covered the tsunami, with 11 saying it placed about the right importance on it. Likewise they were generally happy with the way their coverage was used, with 12 saying it was used either very well or adequately. They also felt well supported by their head office while covering the event, with 11 saying the support was either excellent or good. One said some reporters were ill-prepared: 'Perhaps because they were too inexperienced, both as reporters and because they were simply too young'. Another said there was not enough help with travel and guidance. The feedback given was only negative and they were asked to cover too big an area.

None of the journalists raised any concern about the participant/observer dilemma, although this was not asked specifically. This may have reflected the fact that most would have arrived in the days following the disaster, when relief agencies were already at most of the scenes.

Given the emerging literature about the effects on journalists of covering trauma, it might have been expected that a high proportion would have reported some effect, especially given the horrific sights and smells of the disaster areas. About half described feelings of sadness associated with covering the event due to the impact on the victims. Another said that the sadness was because it was the highlight of their career and was now over. Of the rest, two said it had had a small impact on them, while four said it had no effect, or did not reply.

Asked whether there were any situations they found uncomfortable, six reported yes, and five said no. Of those who replied yes, half (all of seven or more years experience) said this was due to seeing dead bodies and the associated smell, one said it was the poor accommodation they lived in, one said it was seeing the plight of the children of victims, and one said it was because of having to make judgments of another culture. It has subsequently been suggested by one tsunami journalist that more would have answered yes to this question if a less impersonal survey method had been chosen, such as personal interviews.

160 PACIFIC JOURNALISM REVIEW 11 (2) 2005 
Although several were obviously working under difficult conditions, only one reported feeling pressured to provide coverage, and said that that came from within, rather than from supervisors. Interestingly, even though many reported being affected by the event, only three reported that they had counselling for this, and that this was because their employer insisted.This does not take into account the level of mutual support between journalists and friends that may have existed in the field or later. Eight said they had had none, while two did not reply. Some of the answers seemed to hint at a degree of trauma:

This was one of the most emotionless jobs I have covered, a situation that those outside the assignment can't understand. I have discussed this with other journos who were there, and some agree. While I was there, in the week following the event, most affected were dead, the survivors had moved on and we had little contact with them, and the emergency services had their 'professional faces' on. As an organisation we need to address several matters regarding deploying people to these events, and how they are assigned while in theatre. The debrief that was conducted was potentially destructive, and little will have been gained by those involved in it.

Or this from another who had not had counselling:

Just the sheer sadness of it all. Difficult to understand a person's loss when their entire family/extended family/village is gone. One little girl in particular I still wonder about.

And another:

Of course. You can't not be affected when confronted with suffering on such a scale and when you see death and devastation on such a scale. It was truly horrific. It stunk to high heaven and they were people causing this smell. The piles and piles of rotting corpses was the most appalling thing I've ever seen. But it was also a privilege to be there. It was history. It was heart-warming too. In Thailand people were incredibly welcoming and generous despite it all. I half-expected sleepless nights when I got back but it didn't happen. That's not to say you don't think about it and see images in your head sometimes, but it hasn't been a problem as such. It gives life a new perspective. 
Others were more positive:

It is impossible to go to a region like this at this particular time and not be affected. A comprehensive debrief at the end of the trip was fantastic. As a journalist it was an amazing experience to be part of and it has left a lasting impression on me.

Other uncomfortable situations reported included how to report death and what kinds of images were appropriate to be used. Only two journalists acknowledged having used anything approaching a staged photo. One used a photo of a New Zealand volunteer at a body farm posing by some coffins, due to a pressing deadline. Another, a TV journalist, had this to say:

Sometimes it is the very nature of our job in television that we have to ask people to do something, and then do it again because we need to capture the shot at different angles, close-ups and wides, so that we can edit a story together. Is the repeat performance an example of a 'staged shot'? ... What about if a politician or celebrity or even a forensic specialist sets up a photo opportunity [as all three did in tsunami hit areas] ... is this a staged' photo? ... A shot completely set up by a cameraman/ photographer [and made to look as if it wasn't] though, is unethical to me and if I was aware of this happening I would not use the shot in question.

Another said the use of photo opportunities was a concern. S/he described a staged handout of aid, in which villagers were photographed receiving rice, which was then taken off them. The reporter said the villagers were left confused. As the only reporter there, s/he reported on the event, including the staged nature of it.

The conflict between the priorities of aid organisations and the media came up in a different way for another journalist:

I was on Nias Island (predominately earthquake-affected but also affected by the Boxing Day tsunami too) hoping to get a flight back to Medan. There were plenty of flights out of Nias but they were all filled with seriously injured people. We were presented with an opportunity to pay our way onto a flight, but we would have taken the place of sick people who obviously needed it a lot more than us. This is the kind of 
ethical dilemma a journalist facing a deadline can encounter. Instead of taking the flight we opted to wait. Luckily we got a chance flight at the end of the day when there were no more injured people to be evacuated at that point in time. All journalists make their own decisions at times like this.

The above responses are an indication of the situations journalists found uncomfortable. However, it is possible that there were many unethical situations encountered that more specific survey questions may have revealed.

One issue not canvassed by any of the journalists was the effect on the victims of being interviewed. A psychologist who has worked in Phuket since the tsunami has described the negative effects on about five or six children who lost parents who were repeatedly interviewed by the media. She said the children appeared to become numbed by having to repeat their experiences in superficial interviews which did not allow them to work through their deeper feelings fully. She said even adults appeared mildly traumatised by the media, because being interviewed created an expectation that they would receive help. When this was not forthcoming their feelings of loss were reinforced (U. Panyawut, personal communication, 20 May 2005).

As a result of these findings, a follow-up questionnaire was sent to journalists to gauge the extent to which they considered such issues when out in the field. Four journalists replied to the follow-up questionnaire. Although a low response rate, the results are interesting, if not conclusive. The respondents did think about and were clearly sensitive to the state of the survivors. Asked what state of mind they thought their interviewees were in, they gave quite differing responses. One thought those s/he interviewed 10 days after the disaster were 'functioning well' while another interviewing at the same time thought:

People were grieving but were also still in shock. Very difficult to describe in words, but generally high levels of despair and hopelessness. As they were often still in tears, or easily reduced to tears, their state of mind was reasonably obvious.

This discrepancy may be explained by another's perception:

The victims I spoke to were all in Thailand, mainly in the worst hit region of Khao Lak. They were - as were all Thai people - matter of 
fact about the destruction. There were no tears, no laying blame ... no wishing for anything different. This is the way they see the world.

However, as the survey did not ask reporters to specify which region they covered, it did not identify cultural or national variations in attitudes. Two of the four respondents had interviewed children. Asked whether they thought this had had an impact on the children, one said:

No effect at all. They had seen hundreds of journalists before I got there but also, they just weren't affected by recounting their stories or telling how mum and dad were now gone.

Another said: 'This may sound odd, but I think it possibly helped some children. Clearly, some were too traumatised to speak.' It is not clear whether the children interviewed included those mentioned by the psychologist above as having been affected.

The four journalists all thought victims of disasters deserved special consideration. Two thought compassion should be shown in general terms. All said there were situations in which they would consider not interviewing victims, with one speaking for the others:

Of course. But it comes down to the reporter putting the needs of the individual ahead of the need for a story. In a situation like this, it's not as if there was a shortage of victims, pictures.

Given the range of ethical dilemmas encountered, and the literature suggesting New Zealand journalists are keen for ethical guidance, it might have been expected that journalists would have consulted their relevant codes of ethics at some point. However although all but one said their organisation had a code of ethics, none consulted them. This seems to confirm Tucker's suggestion that codes of ethics don't have much impact on journalists' day-to-day work (p. 213). Only two mentioned situations where they had sought ethical guidance, and that was on whether to show images of dead bodies.

\section{Conclusions}

The results suggest the New Zealand journalists surveyed do have a strong awareness that reporting on an event like this raises ethical issues. Among 
other things, the responses indicate a marked sense of concern for those they are dealing with, and a sentiment that the media's needs should not always over-ride those of individuals or humanitarian organisations. Yet it is curious that despite these journalists' concern for ethical issues, and need for guidance, the NZ ethics codes were of little relevance to their work. Does this mean codes are not a useful way of addressing ethical issues? Or does it mean the codes are so out of touch with the day-to-day dilemmas faced by working journalists that they are seen as irrelevant? Perhaps there is an element of both. It seems clear that there are ethical issues not touched on by the codes of ethics that need addressing. One is the apparent lack of awareness of many of these journalists - and by implication their employers - of the potential effect on their own mental health of exposure to trauma. It is beyond the scope of an email-based survey like this to quantify the scope and depth of PTSD exposure. But it is worrying, given the legal requirements of employers to manage staff exposure to stressful situations, and the increasing evidence that journalists covering these sorts of stories are at risk of PTSD, that so few of these journalists have had counselling. Another concern is the practice of interviewing children who have suffered trauma. Is it really necessary?

At the very least, more thought should be given to training journalists in a safe approach. Likewise, the NZ codes of ethics should address this issue more forcefully, perhaps along the lines of the Dart Center guidelines. Lastly, it is clear that there is a need for further research on the level of training and support needed by journalists covering this kind of situation. It would appear from the above that the current level is uneven and in some areas, inadequate.

\section{References}

BBC World Service. (2004). Discussing danger and trauma. Retrieved September 20, 2005: www.bbc.co.uk/worldservice/specials/1715_reporters/page5.shtml.

Broadcasting Standards Authority. (2004). Free to air television code of broadcasting practice. Wellington.

Cote, W., and Simpson, R. (2000). Covering violence: a guide to ethical reporting about victims and trauma. New York: Columbia University Press.

Council of Trade Unions. (2002). National party made police liable for employee stress. Retrieved September 10, 2005: www.union.org.nz/news/64.html.

Dart Center for journalism and trauma. (2005). Tips and tools, covering the tsunami. Retrieved September 5, 2005: www.dartcenter.org/tips_tools/children_trauma.html 
MEDIA ETHICS AND ACCOUNTABILITY

Feinstein, A., Owen, J., and Blair, N. (2002). A hazardous profession: war, journalists and psychopathology. American Journal of Psychiatry, 159, 1570-75.

Griffin, G. (1995). Shoot first: the ethics of Australian press photographers. Australian Studies in Journalism, 4, 3-29.

Hargrave, P.A., Scott, K. M., and McDowell, J. (2005). To resolve or not to resolve: past trauma and secondary traumatic stress in volunteer crisis workers. Journal of Trauma Practice (in press) (2005).

Hirst, M., and R. Patching, R. (2005). Journalism ethics, arguments and cases. Melbourne: Oxford University Press.

Lealand, G. (2004). Still young and female: a (modest) survey of New Zealand journalists. Pacific Journalism Review, 10(2):173-96.

MacLean, S. (2005, March 17). Tsunami blitzes crisis coverage. The Australian, p. 20.

Nelson, A., and Nelson, D. (2001). Practical suggestions for journalists covering catastrophe. Columbia Journalism Review, September-October 2001. Available at: www.cjr.org/year/01/5/coveringcatast.asp

Norris, F. H., Friedman, M. J., Watson, P. J., Byrne, C. M., Diaz, E., and Kaniasty, K. (2002). 60,000 disaster victims speak: part I. An empirical review of the empirical literature, 1981-2001. Psychiatry, 65(3):207-39.

New Zealand Press Council. (1999). NZ Press Council statement of principles. Wellington: New Zealand Press Council.

OSH. (2003). Healthy work: preventing stress and fatigue in the workplace. Wellington: Department of Labour Occupational Safety and Health Service.

Palm, K. M., Polusny, M. A., and Follette, V. M. (2004). Vicarious traumatization: potential hazards and interventions for disaster and trauma workers. Prehospital and Disaster Medicine, 19(1)73-78.

Richards, I. (2005). Quagmires and quandaries: Exploring journalism ethics. Sydney: UNSW.

Sykes, J., and Green, K. (2003). The dangers of dealing with journalists. ANZCA03 conference, Brisbane. Retrieved May 20, 2005: www.bgsb.qut.edu.au/conferences/ ANZCA03/Proceedings/papers/sykes_full.pdf.

Tucker, J. (Ed.). (2001). Intro: a beginnerer's guide to professional news journalism (2nd Ed.). Wellington: New Zealand Journalists Training Organisation.

Varley, C. (1997). Legislating from within. Australian Journalism Review, 19(1): 105118.

Wheeler, T. H. (2002). Phototruth or photofiction: ethics and media imagery in the digital age. London: Lawrence Erlbaum Associates.

James Hollings is a journalist with 18 years experience in newspapers and radio, both in New Zealand and overseas. He has also co-directed and produced two film documentaries, The Whirling Man, and The Last Post. He is currently teaching journalism at Massey University's School of Journalism in Wellington. The author notes:

166 PACIFIC JOURNALISM REVIEW 11 (2) 2005 
Copyright of Pacific Journalism Review is the property of Auckland University of Technology and its content may not be copied or emailed to multiple sites or posted to a listserv without the copyright holder's express written permission. However, users may print, download, or email articles for individual use.

http://Mww.aut.ac.nz/depts/commstud/journ/pjrsubs.shtml 